\title{
Growth Hormone Secretion Abnormality
}

National Cancer Institute

\section{Source}

National Cancer Institute. Growth Hormone Secretion Abnormality. NCI Thesaurus. Code C62800.

An abnormal production of growth hormone. 